\title{
Principios y valores éticos en las organizaciones bancarias respecto a la calidad del servicio y atención al cliente
}

Romero, Gerardo E.*

\section{Resumen}

Este artículo revela mediante un análisis descriptivo la relación de los principios y valores éticos profesados por las organizaciones bancarias en los procesos de la calidad del servicio y atención al cliente, a través de la identificación de los valores, creencias y actitudes presentes en su cultura organizacional. Se llevó a cabo una investigación descriptiva, transversal y de campo para darle respuestas a los objetivos planteados. Las conclusiones estuvieron orientadas a que los principios éticos no son entendidos en igual orden de importancia y que los valores éticos son determinantes para ofrecer calidad y buena atención en los servicios financieros; sugiriéndose algunos lineamientos gerenciales con la creación e implantación de un código ético del comportamiento laboral para garantizarle la preservación y protección tanto del usuario como los miembros de las instituciones bancarias con un espíritu de servicio bajo un enfoque integral ético.

Palabras clave: Principios éticos, valores éticos, calidad del servicio, atención al cliente y organización bancaria.

\section{Ethical Principles and Values in Bank Organizations in Relation to Quality of Service and Client Attention}

\begin{abstract}
This article reveals the relation between ethical principles and values professed by banking organizations in processes of quality of service and client attention through the identification of values, beliefs and attitudes present in its organizational culture, and through descriptive analysis. Transversal descriptive field research was undertaken to reply to the objectives proposed. The conclusions were oriented towards the ethical principles proposed and are not understood in the same order of importance and that ethical values are determining factors in the offer of good quality attention in finan-
\end{abstract}

Recibido: 06-03-07. Aceptado: 06-10-30

* Profesor Agregado de la Universidad del Zulia. Núcleo COL. Administrador, Magíster en Gerencia de Mercadeo. Doctor en Ciencias Gerenciales. E-mail: gerardoeromero@yahoo.com 
cial services, suggesting certain managerial lines for the creation and implementation of an ethical code for labor conduct in order to guarantee the preservation and protection of both the users and the members of banking institutions in a spirit of service within a integral ethical focus.

Key words: Ethical principles, ethical values, quality of service, client attention, bank organization.

\section{Introducción}

El sentido de la ética merece destacarse como pilar fundamental dentro de las organizaciones, porque el hombre debería estar decidido a conducirse de forma oportuna a su conciencia moral, fruto de la cultura del ser y satisfacción de los buenos hábitos en cualquier ámbito. Dentro de esas organizaciones, se encuentran las bancarias, que al parecer, su gerencia se ve tentada a violentar sus normas morales, sin preservar un código de conductas que normatice el cumplimiento formal de la calidad del servicio mediante una excelente atención al cliente, porque los gerentes no estimulan juicios moralistas para ser profesados por los empleados y cumplir con las expectativas de los clientes. Frente a está problemática, se presenta la siguiente interrogante: ¿Cuáles serían los principios y valores éticos en las organizaciones bancarias respecto a la calidad del servicio y atención al cliente?

En ese sentido, se llevó a cabo una investigación descriptiva, transversal y de campo para darle respuestas a los objetivos planteados por dicha interrogante, tales como: determinar los principios y valores éticos en las organizaciones bancarias respecto a la calidad del servicio y atención al cliente; identificar los valores, creencias y actitudes presentes más resaltantes dentro de la cultura organizacional de las empresas bancarias, describir los principios y va- lores éticos presentes en las organizaciones bancarias respecto al proceso de calidad del servicio y respecto al proceso de atención a los clientes, y formular lineamientos para la creación de un Código ético del comportamiento laboral en los servicios bancarios en cuanto a la importancia y convicción de los principios y valores éticos respecto a la calidad del servicio y atención al cliente.

La población estudiada quedó conformada en tres subgrupos, la primera, por los doce gerentes de las agencias principales correspondientes a las organizaciones bancarias universales ubicadas en el Municipio Maracaibo del Estado Zulia: Fondo común, Provincial, Caribe, Venezuela, Corpbanca, Sofitasa, Mercantil, Banesco, Banco Exterior, Citibank n.v., Banco Caroní y Banco Occidental de Descuento. La segunda, integrada por los ciento nueve trabajadores aproximadamente que desempeñan en los puestos de atención al cliente; y la tercera, por los treinta y ocho mil cuatrocientos cincuenta usuarios actuales según censo realizado a dichas agencias.

La información se obtuvo mediante una entrevista dirigida a los gerentes bancarios y dos cuestionarios estructurados dirigidos a los empleados y los clientes bancarios. El estudio se justificó porque se introduce el tema de la responsabilidad ciudadana sin diluir el de la responsabilidad laboral dentro de las entidades bancarias. 


\section{Consideraciones fundamentales acerca de los principios y valores éticos en las organizaciones bancarias}

La ética es el conjunto de principios y valores que hace más humana y meritoria la convivencia entre los hombres. Los principios se fundan como paradigmas morales para ser aplicados mediante una correspondiente necesidad de clarificación y de discusión pública; estos son conocidos independientemente y previamente antes de su aplicación. Los valores son las ideas abstractas regidas por el pensamiento y acción para soportar la cultura, visión y misión de una persona.

En una organización, vendrían a ser las creencias radicadas en el negocio y en su gente para guiar la estrategia organizacional. La ética empresarial está ajustada para desvanecer conflictos existentes en la organización mediante una reflexión moral que ayude el trazo de las discusiones y maniobras con acuerdos justificados apropiados a la conducta (Cortina, 1996).

Las relaciones encausadas hacia los valores auténticos se logran con la cooperación de un código de conducta para minimizar el conflicto, engendrándose así la cultura organizacional bajo principios y filosofías de cómo deben llevarse el negocio (Thompson et al, 1999). En los últimos años, los trabajadores han adoptado una posición diferente frente al cliente, dándose cuenta de que el consumidor exige más en las implicaciones de la ética en la calidad de los bienes y servicios, y reclaman muestra de honradez, trato humano y cordialidad (Rosales, 1995).
Los empleados de atención de los servicios bancarios deben comprender su papel en el desarrollo de la satisfacción de los clientes, convencido de que la formación y motivación ética son radicales para alcanzar dicha satisfacción. El desarrollo de normas éticas con características corporativas producen una mejor calidad y mayor satisfacción del cliente, bajo una interacción entre directivos y empleados de cara al público (Denton, 1991). Cada vez crece la necesidad del cliente para ser atendido rápido y personalizadamente por una institución con imagen sólida y estable (Fernández, 2002).

Entre las cualidades más resaltantes que debe profesar el personal de atención están: credibilidad, honestidad, compromiso, responsabilidad, entre otras. La dificultad se presenta cuando los usuarios de los servicios bancarios en las diferentes entidades parecieran percibir los aspectos de la calidad y la manera de atenderlos son carentes de principios y valores éticos para satisfacer sus expectativas.

\section{Principios y valores explícitos e implícitos presentes en las visiones y las misiones de las organizaciones bancarias}

Es importante resaltar que para este estudio sólo se tomaron en cuenta los principios del compromiso, responsabilidad, respeto, honestidad y credibilidad, ya que a juicio del investigador, estos son esenciales para el buen desenvolvimiento ético de cualquier organización. En cambio, los valores éticos estuvieron dimensionados entre los valores fundamentales y existenciales según la 
axiología de los valores planteados por García y Dollan (1997) y Hoyos (2002). Dentro de los valores fundamentales, se orientaron al prestigio moral personal como valor personal y al ser consecuente con los clientes como valor ético-social. Mientras que los valores existenciales, se enfocaron en la sinceridad en el trato como valor ético-moral y el ser simpático con el público como valor competitivo.

Con el propósito de conocer cuales son los principios éticos profesados por los bancos, se realizó un estudio a las diferentes visiones y misiones de los doce bancos estudiados para así identificar los principios y valores explícitos e implícitos. De los explícitos en las visiones están: garantía, calidad del servicio, solidez, valores éticos y morales, eficiencia, prosperidad, accesibilidad, buen trato y vigilancia, y referente a los implícitos: manera de satisfacer a los clientes, interés por satisfacer las expectativas del usuario, recurso humano capacitado, experiencia en el servicio, satisfacer a la comunidad, liderazgo en el mercado, vocación del servicio y mantenimiento de un desempeño eficiente.

Los explícitos en las misiones son: compromiso, eficiencia, responsabilidad, confianza, ética profesional, integridad, apego a las costumbres, seguridad, moralidad y prosperidad. Mientras los implícitos son: satisfacción de los deseos de los clientes, relaciones de alto valor para todos, satisfacer las necesidades de la comunidad, conocer las necesidades de los clientes, mantener una posición de buen ciudadano corporativo y llegar a ser líder del mercado.

En consecuencia, los principios de compromiso, responsabilidad, respeto, honestidad y credibilidad no están explícitos ni implícitos en la mayoría de las visiones y misiones de los bancos. Tampo$\mathrm{co}$, se encuentran definidos los valores fundamentales $\mathrm{e}$ instrumentales para ofrecer este tipo de servicio, tales como: prestigio moral personal, ser consecuente con los clientes, sinceridad en el trato y ser simpático con el público.

\section{Principios y valores éticos presentes en los bancos}

Gracias a los datos obtenidos de los diferentes instrumentos aplicados a los gerentes, empleados y clientes de los bancos, se pudo constatar el orden de importancia de los principios: honestidad, respeto, credibilidad, responsabilidad y compromiso (Gráfico 1).

Según los gerentes, la honestidad está en primer orden, y los bancos la profesan a través de una atención sincera de las necesidades financieras de los clientes. Los empleados, dicen ser sinceros al momento de entregar los servicios financieros mientras que los clientes dijeron esperar la mayor sinceridad del personal por ser este valor ético moral. En fin, la honestidad se da por las acciones concretas de la verdad, como un acto pudoroso que demuestra la sinceridad, decencia y moderación de la persona (Voltaire, 1995).

Para los empleados, el principio de la credibilidad está en primer orden mientras que para los gerentes es el último; y quienes opinan que este principio favorece al banco porque así proyectaría una imagen solvente la cual incrementa la cartera de usuarios. En ese sentido, los empleados indicaron que la credibilidad está ligada a los principios de respeto y 


\section{Gráfico 1 Honestidad Respeto Credibilidad Responsabilidad Compromiso}
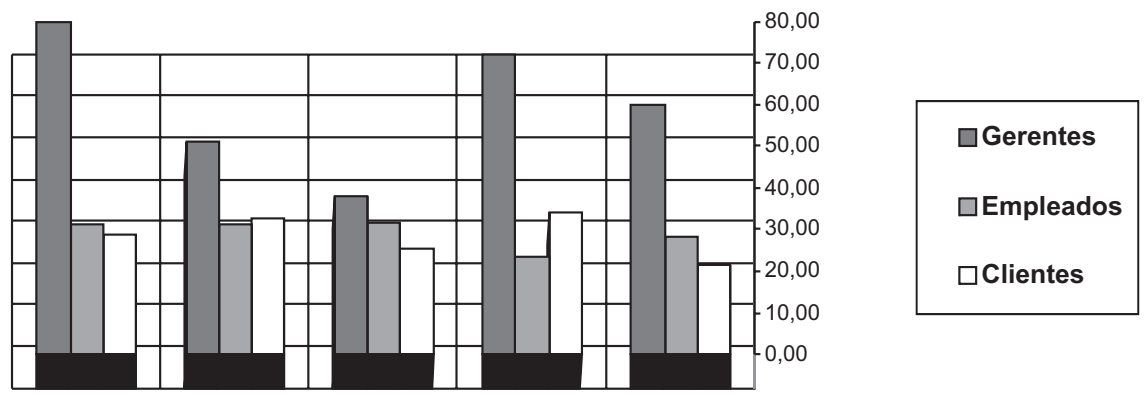

Fuente: Elaboración propia. 2006.

honestidad; y dicha credibilidad, es una característica difícil de evaluar por el consumidor, incluso después de la compra, ya que confían en las pistas tangibles de los servicios para poder creer en ellos (Lamb et al, 1997).

Para los clientes, el principio de mayor importancia ejercido por un banco es el de la responsabilidad, mientras que para los empleados es el último. Para los gerentes es la segunda opción, quienes manifiestan que la responsabilidad se da, cuando los usuarios obtienen los beneficios esperados satisfaciendo sus necesidades; es la acción de cumplir con una obligación, de responder ante sus exigencias (Savater, 1995). Además, los bancos son responsables al protegerles los intereses de los clientes, brindándoles confianza en las operaciones con una demostración de solidez y estabilidad financiera.

Los usuarios ubican en segunda opción, el principio del respeto, mientras que los gerentes lo sitúan en cuarta posición, expresando que los bancos respetan a los clientes por ofrecer transparencia en las operaciones, seriedad en los procesos, tolerancia y accesibilidad. EI respeto lo exige el usuario a las personas que atienden porque consideran que es una actitud profesional necesaria en el proceso de atención. Es un deber moral, es la única actitud natural del hombre frente a su valor y frente de toda persona (Didier, 1983).

Cabe destacar, que para los gerentes, empleados y clientes, el principio del compromiso es la última opción. Los gerentes dicen que las instituciones bancarias se comprometen cuando prometen un servicio de calidad, buena atención, y dan respuestas ágiles y oportunas. Asimismo, se comprometen a respetar los valores del cliente y promover la confianza entre ellos y la sociedad. Sin embargo, este principio de compromiso solamente está explícito en tres misiones de los bancos consultados. En conclusión, el orden de importancia de los principios concebidos por los gerentes bancarios no concuerda directamente con el orden de importancia de los empleados, ni tampoco en el orden dado por los clientes. 


\section{Identificación de los valores, creencias y actitudes presentes y más resaltantes dentro de la cultura organizacional de los bancos}

Para identificar los valores tanto fundamentales y existenciales en la cultura organizacional de los bancos, el investigador infirió que estos se basan en la creencia de que la convicción ética personal es el reflejo del bien común, y que una actitud ética es la buena voluntad en las obligaciones comunitarias para alcanzar una justicia social.

Según la información obtenida entre los gerentes, empleados y clientes, se evidenció que dentro de los valores organizacionales se hayan los personales, específicamente, el prestigio moral de una persona para poder atender. Según los gerentes consultados, los bancos ejecutan procesos de selección del personal con un carácter meticuloso, considerando los valores personales de los interesados a través de un consenso de la actitud anímica del individuo relacionada a la moral, estado mental y emocional que pueda afectar al trabajo (Villegas, 1999).

Los gerentes consideran el prestigio moral parte de la actuación del trabajador, como un valor que impulsa a un alto desempeño de la labor asignada; por eso al momento de reclutar y seleccionar personal, se evalúan las condiciones familiares y del hogar con el propósito de examinar sus valores con la aplicación de cuestionarios conductuales.

Cuando una institución bancaria dice ser consecuente con sus clientes demuestra su valor ético-social. Los gerentes y los empleados opinan que los ban- cos ofrecen sus servicios financieros sin distinciones, pensado siempre primero en los clientes. El ser consecuente con los demás es seguir el orden moral respecto a las cosas y personas, es decir, aquella persona cuya conducta guarda correspondencia lógica con los principios profesados; $y$ aplica un razonamiento de juicio moralista (Voltaire, 1995).

Según los gerentes entrevistados, la sinceridad en el trato al atender al cliente como valor ético moral en los bancos se cumple por que los productos financieros ofrecidos están ajustados a las verdaderas necesidades de los usuarios, al mantener una confidencialidad informativa y no crear falsas expectativas; tal sinceridad es dada con conversaciones sanas y seguras. Mientras que los empleados revelan que la sinceridad es una de las conductas trascendentales la cual delata al personal de atención. Los clientes aprueban la sinceridad como un aspecto necesario en el proceso de la venta, ya que la sinceridad es el ingenio moral de expresarse desprovisto de todo fingimiento mordaz con el propósito de demostrar la honradez y franqueza, que conllevan a la persona o ente a mantener la lealtad de los demás (Savater, 1995).

Un valor competitivo en las instituciones bancarias es la manera simpática cómo debe dirigirse el personal. Los empleados consultados coinciden que la simpatía como ellos tratan a sus usuarios es un valor competitivo digno del personal de atención, ya que es un complemento para la calidad del servicio financiero esperada por el consumidor. De igual forma, los clientes dicen esperar ese trato simpático de parte del personal de atención, ya que esto suma calidad. La 
simpatía son actos hechos intencionales jerarquizados de acuerdo a su mayor o menor intencionalidad, los cuales, el grado superior es al amor.

La creencia profesada por los bancos debe basarse en el bien común a través de la convicción ética de sus trabajadores. Los gerentes opinaron que el convencimiento del personal acerca de la importancia de los principios éticos en las labores es debida a la estimulación de las comunicaciones en valores; los trabajadores deben conocer claramente los valores organizacionales al recibir cursos para su formación moral, ya que profesar el bien común, es una manera adecuada de comportarse de forma conducente, de ser persona y dar valor como persona (Póveda, 2001).

Frente a lo planteado anteriormente, una persona debe estar convencida para consolidarse y desarrollarse como individuo, por lo tanto, debe cumplir con los objetivos empresariales y principios éticos compartidos por todos; en donde su accionar, debe estar permanentemente marcado por la integridad, confianza y lealtad, así como por el respeto y valorización del ser humano en su privacidad, individualidad y dignidad, repudiando cualquier actitud guiada por prejuicios relativos al origen, grupo étnico, religión, clase social y cualquier otra forma de discriminación.

La actitud de justicia social por la buena voluntad para la comunidad, es satisfacer las exigencias con equidad y hacer los esfuerzos posibles para evitar las discriminaciones individuales y sociales. En ese sentido, los gerentes exteriorizaron que la buena voluntad del banco se relaciona con las obligaciones comunita- rias; respetando los deberes sociales y considerando como objetivo primordial el consagrar, el apoyo a las pretensiones colectivas; a través de las labores sociales emanadas de los diversos programas conservacionistas. El banco debe asumir el compromiso competente con los miembros de la organización, con la sociedad y la familia (Serna, 2000).

\section{Relación de los principios y valores éticos presentes en las organizaciones bancarias con el proceso de calidad del servicio}

La calidad de los servicios bancarios se dimensiona a través de los componentes de tangibilidad, confiabilidad, capacidad de respuesta, empatía y seguridad según lo plantean algunos autores tales como: Denton, 1991; Horovitz y Panak, 1997; Lamb et al, 1997; Guiltinan et al, 1998, entre otros. Referente al aspecto de la confiabilidad del producto financiero, esta se refleja a través de la positiva imagen pública la cual debe proyectada por los bancos. Según los gerentes entrevistados, dicha imagen es favorable porque inspira la confianza en los clientes relacionada a su calidad, ya que si una organización es poseedora de una buena imagen, esto sería un factor clave de éxito, que sirve de sello distintivo o de aval para los usuarios.

Los empleados consultados piensan que la imagen positiva es primordial al momento cuando un cliente escoge su entidad financiera, del mismo modo, los clientes exponen que su grado de confiabilidad depende de la imagen del banco incide en un incremento sensible del valor 
de las acciones de la organización. La imagen de un banco constituye la luz propia de las operaciones financieras en un sentido amplio, porque la primera impresión es la que cuenta. No se debe cambiar una imagen para hacerle creer a los clientes la buena voluntad no profesada, una imagen favorable de una empresa beneficiaría a todos, a la organización porque contaría con ese cliente; y al cliente, porque podría confiar en esa empresa (Lamb et al, 1997).

La entrega rápida del servicio como capacidad de respuesta de un banco es lo que el cliente espera; los gerentes opinaron que dicha rapidez es gracias al uso de tecnologías para facilitar el desempeño puntual de lo comprometido. Aunque una minoría de los gerentes entrevistados justificaron la tardanza en la entrega del servicio por que se busca una concienzuda eficiencia en la calidad. Los empleados dicen dar calidad en los servicios porque actúan con celeridad en la ejecución de las operaciones financieras; entretanto, los clientes esperan que le den rápida respuesta para su satisfacción, pues, evalúan la calidad del servicio financiero por su prontitud. Un servicio efectivo, es el servido precisamente cuando los clientes lo esperan, en el tiempo justo y con una calidad confiable (Kazt, 1991).

Los sistemas de información son primordiales como medio para dar respuestas rápidas a tales servicios, adicionándole calidad al bien financiero. Las empresas suelen ser excelentes cuando saben escuchar tanto a sus clientes y empleados y desarrollan un sistema de información para ofrecer en su calidad del servicio, no sólo en estudio, sino, en la práctica a través de una variedad de procedimientos diseñados y ejecutados en práctica en forma profesional (Horovitz, 1997).

Siguiendo con la valoración de la calidad de los servicios financieros, la seguridad del mismo es importante. Los gerentes dicen, ofrecer garantía en las operaciones financieras, por la transparencia e integridad cómo se entrega el servicio y por la gestión estricta de las capacidades para demostrar la lealtad al cliente y consistencia del mismo. Los empleados dicen respaldar con seguridad las operaciones financieras con su trabajo eficiente; en cambio, algunos clientes opinaron que los bancos no cumplen con las garantías dadas. La garantía confirma el desempeño de un producto; existen garantías expresas por escrito e implícitas; aun cuando no estén escritas, el producto ofrecido debe ser apropiado para el propósito por el cual se vendió (Lamb et al, 1997).

Se hallan también los sistemas de protección como medida de seguridad los bancos. Los gerentes dijeron que son congruentes a las expectativas del cliente y apropiados a las recientes tecnologías, al prometer certidumbre y control. Para los empleados, los sistemas de información resguardan las operaciones bancarias requeridas por la clientela. La mayoría de los clientes señalan estar conforme con los sistemas de protección de los bancos. La protección física de una empresa debe ser un aspecto incluido en el proceso de producción; porque esto dice de su capacidad tecnológica e infraestructura (Serna, 2000).

La empatía es otro componente de calidad de los servicios financieros, específicamente, cuando se da una atención vigilante $y$ atenta de parte de los emplea- 
dos al momento de ofrecer el producto. Los gerentes indican que su personal está formado para atender atenta y vigilantemente a los clientes gracias a los constantes programas de formación dirigidos a sus trabajadores para mejorar su atención, involucrándolos como parte esencial del proceso del servicio bancario. La motivación moral en la actuación profesional de un trabajador incide positivamente en los objetivos propuestos por el banco, porque aprenden a resolver problemas cuando se presentan. Los empleados dicen capacitarse para abordar al cliente con una actitud vigilante $y$ atenta. La mayoría de los clientes encuestados estuvieron de acuerdo que son atendidos (Serna, 2000).

Asimismo, la empatía se refleja por medio del trato personalizado en el proceso de atención. Los gerentes expresan que el trato directo con el cliente depende de sus necesidades planteadas; es decir, un trato íntimo que humaniza las relaciones financieras, por eso, los bancos propician ese trato personalizado a través de la accesibilidad ofrecida por la institución bancaria. Los empleados se dirigen al cliente con un trato personalizado, informándole con mayores detalles los atributos del servicio financiero. Por lo general, los usuarios señalan que ese trato personalizado no se da como tal.

El trato personalizado es una estrategia fundamental para dar a conocer al cliente las ventajas del servicio ofrecido y obtener de él, los índices de su satisfacción; además, permite establecer un sistema de postventa y seguimiento para asegurar su lealtad (Serna, 2000) En síntesis, el contacto cara a cara representa la primera herramienta del servicio al cliente, en el que se considera el respeto a la persona, la sonrisa al conversar y las técnicas adecuadas de conversación de acuerdo con la cultura del medio de la empresa. La información adecuada evita actitudes emotivas en el trato, por eso, no se deben dar ordenes al cliente o mostrarles favoritismos.

La calidad del servicio se puede evaluar por los aspectos tangibles. Para los gerentes, los elementos tangibles del proceso de servicio bancario se puede medir gracias a los equipos de alta tecnología utilizados, por eso, los bancos actualizan sus equipos, y prometen un servicio de calidad cónsono a las pretensiones de los clientes, quienes exigen cada vez mayor celeridad del proceso financiero. Esta posición la apoyan los empleados, alegando que los equipos con que cuentan las instituciones bancarias son armónicos con las peticiones del consumidor.

Los clientes confirman las posiciones dichas por los gerentes y empleados, aun cuando, una minoría de los consultados expresaron que no son tan compatibles con las necesidades actuales. La capacidad de una empresa de contar con equipos y maquinarias para el proceso de producción, es una ventaja competitiva, la cual incide en la mejor calidad del producto y mayor satisfacción del usuario (Guiltinan et al, 1998).

De igual forma, la apariencia de las instalaciones en las instituciones bancarias es el principal aspecto tangible del servicio bancario. Según los empleados, el decorado de las instalaciones del banco es importante porque es una muestra tangible de su calidad, mientras que la mayoría de los clientes le dan una moderada importancia 
a la apariencia del decorado del banco como indicador de calidad.

La instalación en la cual se entrega el servicio constituye una parte tangible crucial de la oferta total del mismo; por tal motivo, el mensaje de tangibilidad de una empresa de servicios para el cliente, es por medio de los elementos de decoración, orden y pulcritud del espacio (Lamb et al, 1997). Por lo general, la apariencia del banco es medida por el exterior del edificio, los decorados sobrios, mobiliarios eclécticos y recepciones arquitectónicas, por eso, la estética y arquitectura del local bancario es muestra de la complejidad y desarrollo del proceso financiero, esto es debido a que la imponencia del edificio corporativo forma parte de la imagen del banco quien necesitan proyectar solidez y seguridad.

\section{Relación de los principios y valores éticos presentes en las organizaciones bancarias con el proceso de atención a los clientes}

De acuerdo con Katz (1989); Lovelock (1997); Horovitz y Panak (1997) y entre otros; la cultura de atención de cualquier organización, especialmente las bancarias, puede dimensionarse en la actitud profesional de los empleados y en los modales para la atención. La actitud profesional se refleja en la cortesía ética al cliente, la disposición al cliente y en las relaciones asertivas, mientras que los modales en la atención a través de la amabilidad con los clientes y la apariencia personal.

En ese sentido, los empleados consultados dijeron ser corteses, ya que ésta conducta le añade mayor calidad al servicio ofrecido y el cliente espera ser tratado cortésmente. La cortesía es la demostración que manifiesta la atención, respeto o afecto a una persona; es decir, es la gentileza de un individuo con el prójimo (Voltaire, 1995).

Por otro lado, a juzgar por lo manifestado por las gerentes, la disposición al cliente es la demostración receptiva de las inquietudes emanadas por él respecto al servicio. En ese sentido, los empleados encuestados consideran que están dispuestos a atender y demostrar los principios éticos manifestados por el banco, ya que la disposición para atender es la habilidad ingeniosa y libre de una persona $o$ de un ente, de manifestarle el interés de quererlo ayudar y compartir con ellos la solución de cualquier circunstancia (Ferrater, 1997).

Otra actitud profesional en la atención al cliente son las relaciones asertivas entre la entidad financiera y los clientes. De acuerdo a los gerentes, la existencia de dichas relaciones es necesaria para propiciar y asegurar las nuevas negociaciones y transacciones comerciales bajo una relación ganar-ganar, fomentando una analogía inteligente entre banco y cliente. Esta posición de los gerentes es defendida por los empleados, quienes manifestaron que una relación asertiva diría de los principios y valores éticos profesados por una organización. Las relaciones, entre la organización y el cliente, son provechosas cuando existe un mutuo entendimiento y tienen como propósito el bienestar recíproco (Schuler, 2000).

De acuerdo con los gerentes, la amabilidad de un personal de atención es dada como una acción de esmero del 
banco tan esperada por el cliente; en esencia, la amabilidad del banco es demostrarle al usuario el gusto o placer que siente al momento de atenderlo, procurando hacerlo apreciar la comodidad mientras recibe el servicio. Los empleados dicen que el trato amable de un banco se debe a una acción de orden moral; en igual medida, lo concibe el cliente, aun cuando la minoría opinó lo contrario. En esencia, la amabilidad es la actitud complaciente y afectuosa cuando una persona u organismo se dirige a otros a través de un trato abierto, cordial y gentil.

Por último, la apariencia personal del empleado como un indicador determinante en los modales para la atención. Los gerentes ven dicha apariencia como un principio ético, pues dicen que la uniformidad en la vestimenta y lo bien arreglado que se esté, es vista por el público en general como aquella normativa indispensable en un banco, debido a que el trabajador es la cara del servicio; esta aseveración es declarada similarmente por empleados y clientes. Los modales y el uso del uniforme como vestuario corporativo, son características esenciales para crear las estrategias tangibles en los mensajes del servicio (Lamb et al, 1997).

\section{Consideraciones finales}

Los principios éticos referente a la responsabilidad, honestidad, compromiso, respeto y credibilidad no son entendidos en igual orden de importancia por los gerentes, empleados y clientes los bancos, por lo tanto, es preciso crear un criterio axiológico de los principios y valores éticos para reformular las visiones y las misiones actuales de los bancos.
Los valores éticos referente al prestigio moral de la persona, ser consecuente con el cliente, sinceridad en el trato y la manera simpática como debe dirigirse el personal bancario con los clientes son determinantes para ofrecer calidad y buena atención en los servicios financieros.

En referencia a la creencia de practicar el bien común a través de una convicción ética personal y una actitud de justicia social respecto a la buena voluntad en sus obligaciones comunitarias, son aspectos determinantes para definir claramente la cultura organizacional de la institución bancaria. En esencia, los bancos y sus trabajadores deben respetar al conocer, creer, y hacer cumplir los compromisos éticos de manera equitativa en la comunidad.

La relación de los principios y valores éticos con el proceso de la calidad del servicio se debe a la confiabilidad de la positiva imagen pública proyectada; por la capacidad de respuesta en la rápida e inmediata entrega del servicio y los sistemas de información como medio para dar respuestas de dichos servicios. De la misma manera, por la seguridad en los sistemas de protección empresarial y las garantías ofrecidas; por la empatía a través de la atención vigilante y atenta y un trato personalizado; por la tangibilidad del servicio gracias a los equipos de alta tecnología y la apariencia de las instalaciones de las instituciones bancarias. Asimismo, esta relación entre la ética y la calidad del servicio debe basarse en la credibilidad de los servicios respecto a la tecnología, planes y proyectos planteados por los bancos y por la oferta de este servicio con honestidad. 
La relación de los principios y valores éticos con el proceso de atención a los clientes es el resultado de la actitud profesional asumida por el personal de atención, el cual debe dirigirse con cortesía ética, mayor disposición y propiciar y mantener unas relaciones asertivas entre institución y cliente. Todo esto, condicionado en los modales en la atención mediante un trato de amabilidad y de una impecable apariencia personal proyectada por el trabajador. Los empleados deben mantener, dentro y fuera de la institución, una actitud profesional y discrecional en materia del servicio prestado y rigurosa confiabilidad de la información privada relacionada entre cliente-secreto.

\section{A modo de sugerencias}

Se sugieren los siguientes lineamientos gerenciales dirigidos a los trabajadores de los bancos para su convicción de la importancia de los principios y valores éticos vinculado a la calidad del servicio y la atención al cliente con la creación e implantación de un Código ético del comportamiento laboral para los empleados del banco, teniendo como objetivos, el optimizar el comportamiento ético del personal que labore en las instituciones financieras con relación a los procesos de atención al cliente para garantizarle al usuario la máxima calidad del servicio.

El propósito de dicho código debe partir de la alta gerencia, gestando conciencia de la necesidad para la formación y el adiestramiento de los empleados de atención al cliente. Por lo tanto, su diseño debe servir de manual moralista para orientar al personal en su conducta de trabajo buscando una mayor calidad del servicio bancario; justificado por la razón de que los clientes cada vez más reclaman a los bancos un servicio de mayor calidad y desean ser atendidos respetándose los principios y valores éticos fundamentales y existenciales.

El contenido del Código ético del comportamiento Laboral debería estar esbozado de la siguiente manera:

- Los empleados deben observar, tanto en su vida laboral y privada, las formas de acción ajustadas al ordenamiento legal y a las normas de conductas morales; adoptando un comportamiento fuera y dentro del trabajo bajo un orden moral.

- Todos los miembros del banco deben fundamentar en su creencia en el bien común, teniendo la convicción personal por la ética al momento de llevar a cabo el proceso de atención al cliente para ofrecer alta calidad del servicio.

- Los integrantes que conformen el banco deben tener una actitud de justicia social de buena voluntad con las obligaciones comunitarias.

- El empleado debe apegarse a las más estrictas reglas de los principios de la responsabilidad, honestidad, credibilidad, compromiso y respeto.

- Para un empleado del banco debe ser un prestigio moral personal el ofrecer un servicio bancario con calidad a través de su atención.

- El banco debe tener la capacidad dar respuestas inmediatas a través del trabajador, al entregar rápidamente los servicios financieros.

- El empleado del banco debe ser consecuente con los clientes, demos- 
trándole su exclusividad pero no creando sectarismos entre ellos.

- El personal de atención debe ser sincero con los clientes al momento de ofrecer las bondades y características del servicio financiero.

- El personal de atención debe ser simpático con los clientes colaborando con todas sus dudas, sin caer en abusos en el trato.

- Los empleados bancarios deben ofrecer modales de amabilidad con los clientes sin esperar recibir obsequios o gratificaciones algunas.

- El personal bancario debe guardar y deparar cortesía ética con el cliente mientras se lleve a cabo el proceso atencional.

- Los miembros del banco deben propiciar y favorecer las operaciones bancarias con sus clientes mediante relaciones asertivas.

- El empleado del banco debe velar por el cumplimiento de las garantías contraídas por el banco en resguardo a los derechos del consumidor.

- El banco está en la obligación de ofrecer seguridad con los mejores sistemas de protección tanto para los trabajadores como para los clientes.

- El empleado del banco debe estar siempre dispuesto a atender a los clientes, escuchándoles sus quejas; siendo vigilante y atento frente a cualquier situación.

- El banco debe hacer buen uso de los sistemas de información, garantizando la discrecionalidad de la información suministrada por el cliente.

- El banco debe proporcionar equipos de alta tecnología para ofrecer calidad en los procesos atencionales; el trabajador debe hacer buen uso de los mismos.

- La prestación del servicio bancario se caracteriza por la relación personalizada con el público y exige en consecuencia que los empleados sean preocupados por su apariencia personal y vistiéndose de forma apropiada. Aplicando para esta normativa el uso del uniforme respectivo en condiciones de pulcritud y bien presentado y no usarlos para sitios distintos al lugar de trabajo.

- El banco a través de su personal debe velar por el cuidado de la apariencia de las instalaciones para que estén acorde a las exigencias de los clientes.

- Todos los trabajadores deben fomentar y mantener una imagen pública positiva del banco en el mercado.

- Por último, todos los miembros de la entidad bancaria deberán conocer, respetar, cumplir y hacer cumplir este código ético del comportamiento laboral, para regir la prestación de los servicios bancarios y alcanzar una mayor calidad del mismo mediante de una excelente atención al cliente.

\section{Referencias bibliográficas}

Cortina, Adela (1996). Ética Empresarial. Madrid. España. Simáncas Ediciones.

Denton, Keith (1991). Calidad en el Servicio a los Clientes. $1^{\text {era }}$ Edición. Madrid, España. Ediciones Díaz Santos S.A.

Didier, Julia (1983). Diccionario de Filosofía. Primera Edición. México. Editorial Diana.

Fernández, Leonel (2002). Evaluar la fuerza de venta como factor impulsador de la participación en el mercado 
de las empresas del sector bancario en el Estado Zulia. Universidad Rafael Belloso Chacín Maracaibo-Venezuela.

Ferrater, José (1997). Diccionario de Filosofía. Barcelona España. Editorial Ariel S.A.

García, S. y Dollan, S. (1997). La Dirección por valores. Instituto de Estudios Superiores de la Empresa. España. Editorial Mc Graw-Hill.

Guiltinan, Joseph; Gordon, Paul; Madden, Thomas (1998). Gerencia de Marketing Estrategias y Programas. Sexta Edición. McGraw-Hill Interamericana, S.A.

Horovitz, Jacques y Panak, Jurguens Michele (1997). La satisfacción total del cliente. Tomo 4. Bogotá. McGrawHill.

Hoyos, Guillermo (2002). Educación y ética para ciudadanos. Educación en valores. Bogotá Colombia.

Katz, Bernarde (1989). Como Gerenciar el Servicio al cliente. Santa Fe de Bogotá. Colombia. Legis Editores S.A.

Lamb, Charles; McDaniel, Carl y Hair, Joseph (1997). Marketing. Cuarta Edición: Puerto Rico. ITP International Thompson Editores, S.A.
Lovelock, Christopher (1997). Mercadotecnia de Servicios. Tercera Edición México. Prentice-Hall Hisponamericana. S.A.

Rosales, Ramón (1995). Los servicios Públicos. ¿Para ciudadanos, Clientes o Usuarios? Caracas, Ediciones IESA, serie. Documento de base.

Savater, Fernando (1995). Diccionario de Filosofía. Ediciones Ariel. Barcelona España.

Schuler, Eric (2001). Asertividad. Artes Gráficas COFAS, S.A. España.

Serna, Humberto (2000). Gerencia Estratégica. Planeación y Gestión-Teoría y Metodología. Séptima Edición. Bogotá. Colombia. 3R Editores LTDA.

Thompson, Arthur y Strickland III, A.J. (1999). Administración Estratégica. Conceptos y casos. Décima Primera Edición. México. Mc Graw Hill.

Villegas, José (1999). Administración de Personal. 1era Edición. Caracas. Venezuela. Ediciones Vega, S.R.L.

Voltaire, Francisco (1995). Diccionario de Filosofía. España. Barcelona. 